\title{
Fenomenología
}

\section{Integralidad del ser humano y el cuidado \\ en el proceso salud-enfermedad}

\author{
Integrality of the human being and the care in the \\ health-disease process
}

\section{Integralidade do ser humano e o cuidado no processo saúde-doença}

Iara Micheline Pereira Correa ${ }^{1}$, Elisabete Agrela de Andrade², Gina Andrade Abdala ${ }^{3}$, Maria Dyrce Dias Meira ${ }^{4}$

${ }^{1}$ Enfermeira. Mestranda do Programa de Pós-Graduação em Promoção da Saúde do Centro Universitário Adventista de São Paulo (UNASP/SP). Correo electrónico: iara.correa@osacsc.org.br

${ }^{2}$ Psicóloga. Doutora em Saúde Pública pela Universidade de São Paulo.

Docente Programa de Mestrado em Promoção da Saúde e da graduação em Psicologia no Centro Universitário Adventista de São Paulo (UNASP/SP) e da graduação em Psicologia. Correo electrónico: elisabeteagrela1@gmail.com ${ }^{3}$ Enfermeira. Doutora em Ciências pela Escola de Enfermagem da Universidade de São Paulo - EEUSP. Docente do Programa de Mestrado Promoção da Saúde e da graduação em enfermagem no Centro Universitário Adventista de São Paulo (UNASP/SP). Correo electrónico: ginabdala@gmail.com

${ }^{4}$ Enfermeira. Doutora em Ciências pela Escola de Enfermagem da Universidade de São Paulo EEUSP. Docente do Programa de Pós-Graduação em Promoção da Saúde do Centro Universitário Adventista de São Paulo (UNASP/SP). Correo electrónico: dyrcem@yahoo.com.br

Cómo citar este artículo em edición digital: Correa, I. M. P., Andrade, E. A., Abdala, G. A. \& Meira, M. D. D. (2019). Integralidad del ser humano y el cuidado en el proceso salud-enfermedad.

Cultura de los Cuidados (Edición digital), 23 (54). Recuperado de http://dx.doi.org/10.14198/cuid.2019.54.02

Correspondencia: Estrada de Itapecerica 5859, Jd IAE, C.P. 05858-001; tel. 11 973161029; SãoPaulo - SP

Correo electrónico de contacto: dyrcem@yahoo.com.br Recibido: 22/12/2018; Aceptado: 15/04/2019

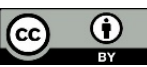

\section{ABSTRACT}

Introduction: Integrality is associated with the various dimensions of life, considering the tangible and subjective aspects related to the complex unity of the human being.

Objective: To promote a critical reflection on the integrality of the human being, in the 
scope of care, as the essence of health practices.

Method: This is a study developed as a reflective essay that approached care in an existential philosophical perspective, aiming at integrality for health promotion.

Development of the theme: Human care, understood as much more than doing or providing care, is projected beyond duty and becomes care and compassion. It covers attitudes that should be part of the analysis and critical reflection of professionals working in the health area.

Conclusion: The recovery of integrality in the health care provided during the practice requires a reflexive posture of the health professional in order to value all the dimensions of the human being, including the spiritual one.

Keywords: Integrality in health, nursing care, health promotion.

\section{RESUMO}

Introdução: A integralidade se associa à várias dimensões da vida, considerando os aspectos tangíveis e subjetivos conexos à complexa unidade do ser humano.

Objetivo: Promover uma reflexão crítica sobre a integralidade do ser humano, no âmbito do cuidado, como essência das práticas de saúde.

Método: Estudo desenvolvido como um ensaio reflexivo que abordou o cuidado em uma perspectiva filosófica existencial, visando a integralidade para a promoção da saúde.

Desenvolvimento do tema: $O$ cuidado humano, entendido como muito mais do que fazer ou prestar assistência, projeta-se para além do dever cumprido e torna-se solicitude e compaixão. Abrange atitudes que devem fazer parte da análise e da reflexão crítica dos profissionais que atuam na área da saúde.

Conclusão: $\mathrm{O}$ resgate da integralidade no cuidado prestado, durante a prática assistencial, requer uma postura reflexiva do profissional de saúde no sentido de valorizar todas as dimensões do ser humano, incluindo a espiritual.

Palavras chave: Integralidade em saúde, cuidados de enfermagem, promoção da saúde.

\section{RESUMEN}

Introducción: La integralidad está asociada diversas dimensiones de la vida, considerando los aspectos tangibles $\mathrm{y}$ subjetivos asociados a la compleja unidad del ser humano.

Objetivo: Promover una reflexión crítica sobre la integralidad del ser humano, en el ámbito del cuidado, como esencia de las prácticas de salud.

Método: Este estudio fue desarrollado como un ensayo reflexivo que aborda el cuidado en una perspectiva filosófica existencial, visando la integralidad para la promoción de la salud.

Desarrollo del tema: El cuidado humano, entendido como mucho más que hacer o prestar asistencia, se proyecta más allá del deber cumplido y se convierte en solicitud y compasión. Abarca actitudes que deben formar parte del análisis y de la reflexión crítica de los profesionales que actúan en el área de la salud.

Conclusión: El rescate de la integralidad en el cuidado prestado, durante la práctica asistencial, requiere una postura reflexiva del profesional de salud en el sentido de valorar todas las dimensiones del ser humano, incluyendo la espiritual.

Palabras clave: Integralidad en salud; atención de enfermería; promoción de la salud. 


\section{INTRODUÇÃO}

Objetivou-se com este ensaio realizar uma reflexão crítica sobre a Integralidade do ser humano e o processo de saúde-doença, abrangendo o cuidado como essência das práticas de saúde. Em seu contexto buscouse a coerência das argumentações, do seu significado e da aplicação nas políticas públicas de saúde do Brasil.

Em outros termos, trata-se de entender os aspectos da natureza humana que se encontram imbricados no conceito de Integralidade, sem os quais, não há como trilhar os saberes filosóficos que orientam o cuidado como objeto de trabalho dos que se empenham em promover a saúde em um contexto de realidade.

Neste sentido, buscou-se ampliar a compreensão da temática, destacando o papel da dimensão da espiritualidade que, por vezes, tem sido deixada em segundo plano, mesmo sendo considerada um aspecto essencial para que a integralidade aconteça de forma efetiva no cuidado.

\section{MÉTODO}

Trata-se de um ensaio reflexivo, desenvolvido em uma perspectiva filosófica existencial, que buscou ampliar o conceito de Integralidade no âmbito do cuidado e da prática assistencial.

O estudo partiu dos aspectos conceituais da integralidade e dos desafios da sua aplicabilidade frente a singularidade e subjetividade de cada pessoa (Arendt, 2010), abrangendo o cuidado em sua natureza epistemológica que envolve todas as dimensões do ser humano. Amparado em Boff (2004), que fundamenta suas premissas ontológicas na mitologia, o estudo buscou refletir na essencialidade do cuidado para garantir e dar significado à vida em toda a sua amplitude.

\section{DESENVOLVIMENTO DO TEMA}

A integralidade consta como o segundo princípio do Sistema Único de Saúde (SUS) implantado no Brasil e é entendida como um conjunto articulado e contínuo de serviços e ações de prevenção e recuperação da saúde exigidos para cada caso, visando o indivíduo e a coletividade em todos os níveis de complexidade do sistema assistencial. No capítulo II das diretrizes do SUS, Lei 8080/90, a integralidade foi mencionada como um princípio que norteia o livre arbítrio, as questões éticas e o respeito pela individualidade, valorizando e entendendo as questões culturais e multidimensionais (Brasil, 1990).

Neste sentido, Arendt (2010, p.119), preconiza que:

"Sendo cada homem um indivíduo singular, no nascimento algo singularmente novo vem ao mundo. O nascimento ou a "natalidade" funda a capacidade de agir e de iniciar algo novo, algo que se renova e traz consigo a persistente novidade e a imprevisibilidade afirmando assim sua singularidade. Neste aspecto, os homens não são politicamente seres para a morte, mas permanentes afirmadores da singularidade que o nascimento inaugura".

Essas características definem a especificidade do ser humano que contemplam uma pluralidade de seres únicos, expostos uns aos outros, em contexto social e histórico. Considera-se nessa interrelação as fragilidades essenciais de toda uma vida submetida a um mundo em que a vulnerabilidade e a efemeridade precedem a própria existência do indivíduo e condicionam o agir de modo intencional que se transforma constantemente (Arendt, 2010).

Ainda, segundo Arendt (2010, p.119) a vida é entendida como:

"[...] um processo em que toda parte consome 
a durabilidade, desgasta-a e a faz desaparecer, até que finalmente a matéria morta, resultado de processos vitais pequenos, singulares e cíclicos, retorna ao gigantesco círculo global da natureza, onde não existe começo nem fim e onde todas as coisas naturais volteiam em imutável e infindável repetição. 'A vida é o ciclo das espécies marcado do nascimento à morte, plena de eventos que ocorrem em um mundo afirmando a singularidade de cada um'".

A integralidade de cada pessoa pode ser compreendida através dos aspectos biológicos, psicológicos e sociais. Desta forma, o cuidar ou prestar assistência adquire um caráter individualizado, com a valorização das interações entre os que cuidam e os que recebem os cuidados, construindo vínculos e promovendo um projeto terapêutico mais acolhedor com vistas à complexidade humana (Paim, 2010).

Essa temática tem sido frequente em pesquisas com reconhecida inserção na prática assistencial devido ao seu ideal regulador pois, entre os princípios que constituem as Diretrizes do SUS, a integralidade se destaca por indicar o resgate das dimensões subjetivas e psicossociais do saber em saúde, norteando o cuidado cotidiano (Wenceslau, 2014).

Nessa perspectiva, a integralidade passa a ser interpretada como uma noção polissêmica, e um valor a ser defendido e sustentado pelo Estado, como um dos princípios do SUS, passando a englobar diversas dimensões do cuidado como: acesso, qualidade da assistência à saúde e as relações interpessoais, considerando cada pessoa em sua totalidade incluindo os aspectos bio-psicológicos, sociais e espirituais (Paim, 2010).

A proposta de Integralidade na saúde surge no Brasil, inicialmente como uma prática médica, na qual as ações de promoção da saúde se misturam com outras práticas da conduta médica como o diagnóstico precoce de doenças, limitação de danos, controle das doenças adquiridas, assim como a reabilitação. Essas propostas aos poucos vão se estruturando e se diferenciando, levando ao surgimento do movimento que se estabeleceu após a lei 8.080/90, com a criação do Sistema Único de Saúde (Paim, 2010).

Valorizar o cuidado integral como uma dimensão essencial da existência humana deve permear todas as experiências e práticas assistenciais. Ressalta-se que não há uma fórmula aplicada igualmente a todos os humanos, porque cada um é uma criatura única e individualizada, em sua essência. Assim, o significado do cuidado adquire uma dimensão ontológica constituída no modo de ser, singular do humano (Boff, 2004, p. 45).

Para demonstrar a essência do cuidado, conta-se uma fábula-mito sobre o cuidado essencial, conhecida como a "fábula de Higino. O autor desta fábula foi um homem grego escravizado pelo império romano, mas, por ser um homem muito culto, acabou sendo liberto pelo imperador romano Augusto (27 a. C. até 14 d. C.) e foi nomeado diretor da Biblioteca Palatina, dando-lhe a oportunidade de escrever vários livros sobre os deuses Gregos e as pessoas ilustres da Cidade de Roma. Entre esses livros, destacase um sobre as Fábulas e Genealogias que reuniram cerca de 300 fábulas e mitos da tradição grega e latina. Um desses mitos citado por Rocha (2011) chama a atenção, pela simplicidade e beleza do conteúdo, a fábula de n. ${ }^{\circ} 220$ sobre a "Cura", traduzida para o português como "Cuidado".

A fábula de Higino é para alguns estudiosos, como Leonardo Boff, uma fábula-mito, pois, em sua dimensão simbólica, o mito revela uma forma de compreensão e de inteligibilidade, diferente 
daquela elaborada pelo nosso conhecimento tradicional, racional e filosófico, utilizando os símbolos e metáforas para elaborar histórias que traduzam uma determinada realidade (Rocha, 2011).

Essa fábula, conhecida como o "Mito de Higino" é descrita por Boff (2004, p. 46) em um contexto carregado de significados quanto à integralidade do ser humano:

"Ao atravessar um rio, Cuidado viu uma porção de barro e teve uma ideia. Tomou o barro e começou a dar-lhe forma. Enquanto olhava o que havia criado, apareceu Júpiter. Cuidado pediu então para que Júpiter soprasse espírito nele, o que fez de bom grado.

Entretanto, quando Cuidado resolveu dar um nome à criatura, Júpiter o proibiu. Exigiu que fosse dado seu nome, pois o sopro de vida transformou aquela criatura em um ser vivente. Enquanto os dois discutiam, surgiu um terceiro personagem, a terra, que após descobrir o motivo da discussão, também queria denominar a criação, entendendo que havia sido feita de barro, material do seu corpo.

Finalmente, para dar fim à disputa, pediram a Saturno que funcionasse como árbitro. E a decisão foi a seguinte: Júpiter deu-lhe o espírito e receberá de volta por ocasião da morte dessa criatura. Terra deu-lhe o corpo e também o receberá de volta após a morte. Mas como Cuidado foi o primeiro a moldar esse ser, ficará sob seus cuidados enquanto ela viver. Sendo seu nome Homem, feito de húmus que significa terra fértil".

Siles González e Solano Ruiz (2007) utilizaram o aporte epistemológico da fábula de Higino para, com base na fenomenologia de Heidegger (2000), resgatar os conceitos de "cuidado" e "cura" que, em um enfoque filosófico e holístico, se integram de forma indissociável e dão sentido à existência humana desde o nascimento até a morte.

Seguindo essa linha de interpretações filosóficas, Queirós (2015) discorre sobre a construção do conceito de cuidado partindo do cuidado de si mesmo como essencial a vida humana, para então se instituir como cuidado do outro. Ampliando suas considerações propõe uma reflexão sobre a grandeza do seu significado no contexto das práticas do enfermeiro que passa a ser entendido como "cuidado integral".

A maneira como os profissionais de saúde lidam e incorporam as atividades de rotina, prestando cuidados, pode fazer com que o cuidar adquira um enfoque tecnicista, no qual se perde as características como a afetividade, o envolvimento, a compaixão e a visão de que aquela "pessoa" que está sendo cuidado é dona de uma história de vida única e de necessidades singulares. $\mathrm{O}$ doente não deve ser caracterizado pela doença ou tratamento, mas sim como uma pessoa que antes de todas essas circunstancias possui valores e crenças próprias. Com essa visão em mente, o cuidado vai muito além do dever cumprido, ele é projetado para a essência do corpo humano, pois considera-o na integralidade do ser (Machado, 2016).

Acerca da importância essencial do cuidado, Boff (2004, p. 89) preconiza que:

"[...] do ponto de vista existencial, o cuidado se acha a priori, antes de toda atitude e situação do ser humano, o que sempre significa dizer que ele se acha em toda atitude e situação de facto. Quer dizer, o cuidado se encontra na raiz primeira do ser humano, antes que ele faça qualquer coisa. E, se fizer, ela sempre vem acompanhada de cuidado e imbuída de cuidado".

Para o mesmo autor supracitado, "compreender a subjetividade do ser humano torna-se essencial para o processo do cuidar que se traduz na solicitude, zelo e bom trato". Essas são consideradas atitudes 
fundamentais do modo de ser humano, em que cada um deve sair de si mesmo e centrar-se no outro com desvelo e solicitude (Boff, 2004, p. 90).

Assim, compreendendo a amplitude e a sincronia das dimensões física, mental e espiritual do ser humano, torna-se importante refletir sobre o papel da espiritualidade em um cuidado que pretende alcançar a integralidade.

Nesse contexto, destaca-se um estudo com 40 usuários da Atenção Básica no Brasil, no qual os resultados demonstraram que, apesar da falta de médicos e da demora para marcação de consultas e exames diagnósticos, os pacientes estavam satisfeitos com o cuidado humanizado que recebiam. Porém, na visão deles, deveria haver "maior comprometimento dos profissionais de saúde em buscar a efetividade de ações contínuas para se promover a integralidade do cuidado em saúde" (Santos et al., 2016, p. 3).

$\mathrm{O}$ cuidar, segundo as teorias da enfermagem, deve acontecer de forma humanizada e integral, não apenas a assistência dos aspectos biológicos, mas também psicossociais e espirituais do ser humano. Os autores sugerem o resgate da integralidade, da humanização, e da unicidade, incluindo a dimensão da espiritualidade como aglutinadora do potencial humano de cuidar (Salviano et al., 2016).

Sobre o "cuidar da integralidade" do ser, em reflexão crítica envolvendo enfermeiros, Santos et al. (2012) afirmaram que o cuidado integral acontece quando todas as dimensões recebem uma atenção holística. $\mathrm{O}$ corpo, a alma e o espírito precisam ser vistos de forma integrada para receberem o enfoque adequado. Corroborando com este enfoque destaca-se um estudo com 101 pacientes de uma clínica médica, no qual
$84,2 \%$ dos participantes acreditavam que cuidar da saúde é também assistir o paciente nas suas necessidades espirituais/religiosas (Oliveira et al., 2013).

Destaca-se ainda um estudo de revisão conduzido por Simão-Miranda et al. (2017) que buscou identificar na literatura estudos que abordavam as atividades de enfermagem envolvendo o cuidado espiritual a pacientes adultos com câncer. Entre os oito artigos analisados constam três artigos experimentais ou quase experimentais cujo nível de evidência foi de II e III. Concluiu-se nesse estudo que deveria haver maior investimento em promover atividades de ensino que estimulem a visão de integralidade do ser humano. Registraram, também, que deveriam ser realizados mais estudos de ensaio clínico para evidenciar a contribuição desse enfoque na prática assistencial.

Vale registrar, ainda, um importante estudo de intervenção educativa, conduzido por Koenig, Perno e Hamilton (2017), aplicada a médicos clínicos e outros profissionais de instituições de saúde confessionais Adventista do Sudeste dos Estados Unidos da América (EUA). A pesquisa evidenciou a importância das ações assistenciais voltadas ao atendimento das necessidades espirituais dos pacientes. Os autores concluíram que programas educacionais são essenciais para mudar a atitude dos profissionais de saúde no que diz respeito a um envolvimento apropriado e sensível no cuidado a ser prestado, abrangendo a integralidade do ser humano.

\section{CONCLUSÃO}

A integralidade do cuidado apresenta-se como um constructo capaz de estabelecer relações mais concretas e plenas entre pacientes e equipe de saúde, rumo ao 


\section{Cultura de los Cuidados}

horizonte, no qual se percebe e se valoriza aspectos humanos inerentes às dimensões envolvidas no cuidado, incluindo a espiritualidade.

Esta reflexão possibilitou compreender que o sentido do cuidado vai muito além da execução de tarefas desenvolvidas no cotidiano do trabalho em saúde. Ele é a essência do ser humano e todos que fazem do cuidado integral o âmago da sua profissão precisam se apropriar da abrangência desse conceito.

Atitudes positivas como a compaixão, solicitude e disponibilidade são aspectos imbricados no cuidado e que devem fazer parte da análise e reflexão dos profissionais que atuam na área da saúde e pretendem o resgate da integralidade do ser humano na prática assistencial.

\section{BIBLIOGRAFÍA}

- Arendt, H. (2010). A Condição Humana. 11.ㄹ ed. Rio de Janeiro: Forense Universitária

- Boff, L. (2004). Saber e Cuidar: Ética do humano Compaixão pela terra. 11. ${ }^{\text {a }}$ ed. Petrópolis, RJ: Vozes

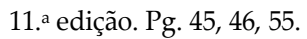

- Brasil. Casa Civil (1990) Lei n.o 8.080, de 19 de setembro de 1990. Brasília. Recuperado de http://www.planalto.gov.br/civil 03/Leis/L8080.ht m.

- Heidegger, M. (2000). El ser y el tiempo. Fondo de Cultura Económica, Madrid.

- Koenig, H. G., Perno, K., Hamilton T. (2017). Effects of a 12-month educational intervention on outpatient clinicians' attitudes and behaviors concerning spiritual practices with patients. Advances in Medical Education and Practice, 2017(8), 129-139. Recuperado de https://doi.org/10.2147/AMEP.S125352.

- Machado, E.R., Soares, N.V. (2016). Humanização em UTI: sentidos e significados sob a ótica da equipe de saúde. Revista de Enfermagem do Centro Oeste Mineiro; 6(3), 2342-2348. Recuperado de http://www.seer.ufsj.edu.br/index.php/recom/artic le/view/1011/1167.

- Oliveira, G.R., Fittipaldi Neto, J., Salvi, M.C., Camargo, S. M., Evangelista, J. L. y Espinha, D.C.M. y Lucchetti, G. (2013). Saúde, espiritualidade e ética: a percepção dos pacientes e a integralidade do cuidado. Revista Brasileira de Clinica Medica, 11(2), 140-144. Recuperado de http://files.bvs.br/upload/S/16791010/2013/v11n2/a3566.pdf.

- Paim, J. S. y Silva, L. M. V. (2010). Universalidade, integralidade, equidade e SUS. BIS. Boletim do Instituto de Saúde (Impresso), 12(2), 109-114. Recuperado de http://periodicos.ses.sp.bvs.br/scielo.php?script=sc i arttext\&pid=S1518$\underline{18122010000200002 \& \operatorname{lng}=p t \& t \operatorname{lng}=p t .}$

- Queirós, P. J. P. (2015). Cuidar: da condição de existência humana ao cuidar integral profissionalizado. Revista Enfermagem Referência, 4(5), 139-146. Recuperado de http://dx.doi.org/10.12707/RIV14079.

- Rocha, Z. (2011). A ontologia Heideggeriana do cuidado e suas ressonâncias clínicas. Síntese: Revista de Filosofia, 38(120), 71-90. Recuperado de http://dx.doi.org/10.20911/21769389v38n120p7190/2011.

- Salviano, M. E. M., Nascimento, P. D. F. S., Paula, M. A., Vieira, C. S., Frison, S. S., Maia, M. A., Souza, K. V. y Borges E. L. (2016). Epistemologia do cuidado de enfermagem: uma reflexão sobre suas bases. Revista Brasileira de Enfermagem, 69(6), 1240$1245 . \quad$ Recuperado de http://www.scielo.br/pdf/reben/v69n6/0034-7167reben-69-06-1240.pdf.

- Santos, D. C., Pinto, D. M. T., Abdala, G. A. y Meira, M. D. D. (2016). Percepção de usuários da Atenção Básica acerca da produção do cuidado. Lecturas: Educación Física y Deportes, Revista Digital, 21(220), 1-4. Recuperado de https://www.researchgate.net/publication/3087245 25_Percepcao_de_usuarios_da_atencao_basica_ac erca da producao do cuidado Perception of us ers_of_primary_care_about_healthcare_productio n.

- Santos, I., Caldas, C. P., Erdmann, A.L., Gauthier, J. y Figueiredo, N. M. A. (2012). Cuidar da integralidade do ser: perspectiva estética/sociopoética de avanço no domínio da enfermagem. Revista de Enfermagem da UERJ, 20(1), 9-14. Recuperado de http://www.epublicacoes.uerj.br/index.php/enfermagemuerj/art icle/view/3967/2750.

- Siles González, J., Solano Ruiz, M. C. (2007) El origen fenomenológico del "cuidado" y la importancia del concepto de tiempo en la historia de la enfermería. Cultura de los cuidados, 11(21), 1927. Recuperado de https://doi.org/10.14198/cuid.2007.21.04. 
- Simão-Miranda, T. P., Monteiro, L. A., Carvalho, C. C., Cordeiro, L. A. M., Chaves, E. C. L. y Leite, M. A. C. (2017). La dimensión espiritual en el cuidado de las personas con cáncer: una revisión integradora. Cultura de los Cuidados (Edición digital), 21(47), 14-21. Recuperado de http://dx.doi.org/10.14198/cuid.2017.47.02.

- Wenceslau, L. D., Rohr, F., y Tesser, C. D. (2014).
Contribuições da medicina antroposófica à integralidade na educação médica: uma aproximação hermenêutica. Interface (Botucatu), 18(48), 127-138. Recuperado de http://dx.doi.org/10.1590/1807-57622014.0745. 